\title{
El control judicial del contencioso administrativo en servicios públicos ${ }^{1}$
}

\author{
Guillermo VArgas Ayala ${ }^{2}$
}

\section{RESUMEN}

No hay dudas de la importancia constitucional que supone el control judicial de la jurisdicción de lo contencioso en materia de servicios públicos. Aprovechando la conmemoración de los 20 años de la Ley de los Servicios Públicos Domiciliarios -Ley 142 de 1994-, este artículo invita a la reflexión sobre la realidad del derecho de los servicios públicos. Luego de una detallada exposición de algunos antecedentes de la jurisdicción de lo contencioso, se expone lo que aquí se denomina zonas de certeza y zonas de incertidumbre competencial del contencioso administrativo en materia de servicios públicos. Al realizar un análisis detallado de la jurisprudencia del Consejo de Estado, se llega a la inevitable conclusión de que la extensión del control contencioso sobre los actos de las autoridades y de los operadores del sector es mucho más amplio de lo que inicialmente

1 Ponencia elaborada para el VIII Congreso Jurídico de Servicios Públicos "Veinte años de la Ley 142 de 1994", organizado por la Universidad Externado de Colombia y ANDESCO, del 26 al 28 de noviembre de 2014. Esta versión está actualizada y adaptada al formato de la revista. Fecha de recepción: 1 de diciembre de 2014. Fecha de modificación: 17 de diciembre de 2014. Fecha de aceptación: 17 de diciembre de 2014.

Para citar el artículo: VARGAS AyAla, G. (2014). "El control judicial del contencioso administrativo en servicios públicos", en Revista Con-texto, nº. 42, pp. 11-35. DOI: http://dx.doi.org/10.18601/01236458. $\mathrm{n} 42.03$

2 Abogado y especialista en Derecho privado, Derecho administrativo y Derecho urbano de la Universidad Externado de Colombia. Profesor universitario de pregrado y posgrado de la Universidad Externado. Se ha desempeñado como abogado y jefe de la Oficina Jurídica del Instituto Nacional del Transporte, jefe de la Oficina Jurídica del Ministerio de Salud, abogado en la oficina Vargas Rubiano Abogados, asesor jurídico ASINFAR, asesor jurídico de la Sociedad Colombiana de Arquitectos, socio honorario de la Sociedad Colombiana de Arquitectos, conjuez de la Sección Primera del Consejo de Estado, Consejero de Estado. Actualmente,Magistrado del Consejo de Estado, Sección Primera. Correo-e: despachovargasayala@gmail.com. 
se pensó. El administrativo se resiste a dejar de ser el derecho de los servicios públicos y el contencioso persiste en ser el juez del interés general y de las prerrogativas públicas.

Palabras clave: Servicios públicos ${ }_{i}$ Control judicial ${ }_{i}$ Jurisdicción de lo contencioso administrativo; Interés general.

THE JUDICIAL REVIEW FROM THE ADMINISTRATIVE JUSTICE OF THE PUBLIC UTILITIES LAW

\section{ABSTRACT}

It is beyond question the importance of judicial review of the administrative justice in public service law. In this special occasion -this year, 20 years of the public service statute will be commemorated- this paper invites its readers to ponder about the reality of public utilities law. After a very detailed review of some of the most important historic moments of the administrative justice, the author presents what he calls zones of certainty and zones of uncertainty in the jurisdiction of the administrative courts on the topic of public services. Conducting a very detailed analysis of precedent from the Consejo de Estado -Colombia's highest administrative court- the author reaches an inevitable conclusion, the extension of the judicial control power over the matters of public services are far wider than it was originally intended. Administrative law insists on being the law of public utilities and its jurisdiction persist on being the judge of public interest and prerogative powers.

Keywords: Public Utilities ${ }_{i}$ Judicial Review $_{;}$Administrative Justice ${ }_{i}$ Public Interest.

1. INTERMITENCIAS DEL CONTROL JUDICIAL DE LOS SERVICIOS PÚBLICOS POR PARTE DEL CONTENCIOSO ADMINISTRATIVO

\subsection{Algunos antecedentes}

El Consejo de Estado fue creado por el Libertador en Angostura, en 1817, con funciones consultivas. Abolido en la Constitución de 1843, este órgano reaparecería con la Constitución de 1886, que lo previó como órgano supremo de lo contencioso administrativo "si la ley estableciere esta jurisdicción" (arts. 141 num. $3^{\circ}$ y 164). Años después, volvería a ser suprimido por el Acto Legislativo n. ${ }^{\circ} 10$ de 1905, para ser definitivamente restablecido por el acto reformatorio de la Constitución n. ${ }^{\circ} 3$ de 1910, que en su artículo 42 impuso a la ley el mandato de establecer y organizar la jurisdicción de lo contencioso administrativo. El cumplimiento de esta encomienda tuvo lugar en 1914 con la expedición de la Ley 130 de 1913, primer código contencioso administrativo del país, y luego 
con la Ley 60 de 1914, que organizó el Consejo de Estado, lo dividió en dos salas (la de negocios generales y la de lo contencioso administrativo) y le otorgó las funciones referentes esencialmente a las controversias originadas en el ejercicio del poder público por parte de las autoridades, que la ley 130 de 1913 le había atribuido al Tribunal Supremo de lo Contencioso Administrativo ${ }^{3}$.La contencioso administrativa nacía así como una justicia especial que buscaba responder a la preocupación por especializar y concentrar el control judicial de la Administración en un órgano independiente de la justicia ordinaria ${ }^{4}$, e inició sus labores con una clara vocación de asumir el conocimiento de los litigios llevados a los tribunales por los ciudadanos para "oponerse a los actos

3 Artículo 18. El Tribunal Supremo conoce privadamente en una sola instancia de los asuntos siguientes:

De los negocios sobre suministros, empréstitos y expropiaciones en tiempo de guerra,

De las reclamaciones sobre recompensas militares;

De las actuaciones sobre reconocimiento de pensiones conforme a la ley;

De los asuntos relativos a la navegación marítima o fluvial de los ríos navegables en que se ventilen cuestiones de mero derecho administrativo, en cuanto no sean de la competencia exclusiva de la Corte Suprema de Justicia;

De las causas o negocios contenciosos sobre presas marítimas;

De las cuestiones que se susciten entre el Estado y uno o más Departamentos o Municipios sobre competencia de facultades administrativas;

De las cuestiones que se susciten entre dos o más Departamentos sobre competencia de facultades administrativas;

De las cuestiones respecto a la condición de ocultos que tengan los bienes denunciados como tales, en los casos previstos en el aparte f) del artículo 30 del Código Fiscal ${ }_{i}$

De los recursos contencioso-administrativos contra las resoluciones de los Ministros, que pongan fin a una actuación administrativa, con excepción de los que se originen en contratos celebrados en nombre del Estado; pues las acciones contra estas últimas providencias sólo pueden ejercerse ante la justicia ordinaria.

Artículo 19. El Tribunal Supremo conoce en segunda instancia de los asuntos siguientes:

De las apelaciones contra las sentencias dictadas por los Tribunales Administrativos Seccionales, sobre la validez o nulidad de las Ordenanzas u otros actos de las Asambleas Departamentales que hayan sido acusados como violatorios de la constitución o de las leyes, o lesivos de derechos civiles;

De las apelaciones contra los autos interlocutorios o de sustanciación, y las tendencias de excepciones pronunciadas por los Recaudadores Nacionales y los Jueces de Ejecuciones Fiscales;

De las apelaciones contra los autos de fenecimiento pronunciados por la Corte de Cuentas contra los Ministros liquidadores o el Ministro ordenador de que trata el Código Fiscal ${ }_{i}$

De las apelaciones contra los autos de imposición de multas dictadas por la Sala de Decisión de la Corte de Cuentas o por los Tribunales Administrativos Seccionales, y

De las apelaciones contra las sentencias dictadas por los Tribunales Administrativos Seccionales en los juicios iniciados sobre el monto, distribución o asignación de los impuestos nacionales.

Artículo 20. El Tribunal Supremo conoce en tercera instancia de las apelaciones contra los autos de fenecimiento con alcance dictados en segunda por la Sala de Decisión de la Corte de Cuentas.

Artículo 21. El Tribunal Supremo conoce por consulta de los asuntos siguientes:

De las sentencias dictadas por los Tribunales Administrativos Seccionales, sobre la validez o nulidad de las Ordenanzas u otros actos de las Asambleas Departamentales, cuando aquéllas no hayan sido apeladas, y

De los autos absolutorios proferidos por la Sala de Decisión de la Corte de Cuentas en los Casos previstos por el Código Fiscal. 
arbitrarios, dañinos e ilegales del Estado" (HERNÁNDEZ BECERRA, 2011 : 390), asuntos que se consideraban propios de una jurisdicción distinta.

Posteriormente, la Ley 167 de 1941 adicionó a la jurisdicción de lo contencioso administrativo el conocimiento de litigios derivados de la responsabilidad extracontractual del Estado. Años más tarde, el Decreto 528 de 1964 le asignó competencia en temas de diferencias contractuales, hasta entonces del conocimiento de la justicia común. Así se perfilaría el contencioso administrativo que hoy conocemos, el cual, como pasa a verse enseguida, ha ejercido un papel diverso en el ámbito de los servicios públicos.

\subsection{Del contencioso administrativo como juez de los servicios públicos al contencioso administrativo como juez de excepción en materia de servicios públicos}

Las reformas constitucionales llevadas a cabo entrado el siglo XX, en especial las de 1936 y 1968, siguieron las tendencias francesas imperantes en Europa, que concebían y justificaban el Estado como un gran prestador de servicios públicos, y aupados por la jurisprudencia orientada en el mismo sentido, los servicios públicos se convirtieron en un eje socio-político esencial de la justificación de la administración del Estado. Lo anterior significó, en su momento, no solo la ampliación del objeto de la jurisdicción, sino una comprensión más amplia de "lo administrativo", al pasar de entenderla como un particular ejercicio de prerrogativas estatales a aplicar un criterio más genérico como el de la prestación de servicios públicos.

Al cabo de esta evolución, el contencioso administrativo termina convertido en el juez del interés general, lo cual tiene lugar en un contexto en el cual el servicio público es monopolio estatal. En términos generales, el contencioso administrativo es el juez de los servicios públicos y el Derecho aplicable a estos supuestos será el régimen especial del Derecho Administrativo. La regla es, la siguiente: 1) el prestador del servicio es siempre una entidad estatal (monopolio estatal); 2) por la doble circunstancia de tratarse siempre de entidades estatales que además prestan servicios públicos, el juez competente es invariablemente el Contencioso Administrativo, y, por último, 3) el Derecho aplicable es siempre el Derecho administrativo.

En un primer momento, las disposiciones de la Constitución Económica ${ }^{5}$ de la Carta de 1991 inicialmente, y la Ley 142 de 1994 (LSPD) después, modificaron la arquitectura de los servicios públicos de manera significativa: por una parte, establecieron que la garantía de su prestación eficiente corresponde al Estado, al igual que su regulación, inspección, vigilancia y control, por lo que además se señala de manera expresa que su régimen jurídico deberá ser fijado por el legislador. Por otro lado, termina el monopolio

5 Sobre la Constitución Económica, categoría jurídica introducida de manera general por el constitucionalismo social para hacer referencia al conjunto de cláusulas que establecen el marco general de la estructura y funcionamiento del sistema económico, aspecto anteriormente "ajeno" a los textos constitucionales por estar remitido a la mano invisible, es amplia la bibliografía. Cfr., entre otros, CORREA Henao (2008), Santaella Quintero (2001), Julio Estrada (2000), Velilla Moreno (1996) y Brewer CARÍAS (1991). 
estatal de su prestación, abriéndola a la prestación privada, alterando drásticamente la relación antes descrita. A partir del cambio de modelo implantado, la calificación de una actividad como servicio público dejó de ser sinónimo de un régimen jurídico especial de Derecho Administrativo y de sometimiento de estas controversias al contencioso. La opción general por el Derecho Privado como régimen de los actos y contratos de las ESP supuso así una ruptura notable del esquema clásico nacional, impulsada por la denominada concepción económica de los servicios públicos acogida por la Constitución y la ley. Siguiendo la línea marcada por el neoliberalismo tan en boga en lo político y económico por esos años y por la denominada buida del Derecho Administrativo ${ }^{6}$ entonces imperante en lo jurídico, "[1]as reformas legales del año 1994, en desarrollo del modelo económico constitucional previsto en el capítulo V del Título XII de la Carta de 1991, comportaron la sustitución del viejo esquema de prestación de los servicios públicos domiciliarios en Colombia -que, siguiendo muy de cerca las enseñanzas de la escuela realista de Burdeos liderada por el profesor Duguit, asimilaba la noción de servicio público a la de función pública y que había entrado en crisis- por un modelo de mercado en competencia que concentró en el Estado, en su condición de director general de la Economía, las atribuciones de regulación y control" ${ }^{\prime \prime}$.

Amparado por el nuevo marco constitucional y animado por el deseo de mejorar los niveles de calidad, cobertura y eficiencia de la prestación de los servicios públicos, el legislador de 1994 quiso valerse de las ventajas de la promoción de la libre competencia y de los mercados para realizar estos objetivos. En palabras de Palacios Mejía, "[e]1 propósito general de la Ley 142 es lograr eficiencia y equidad en la prestación de los servicios públicos. La ley supone, con base en la teoría económica, que, por regla general, la eficiencia se alcanza en la medida en que se permita que haya muchos proveedores de servicios públicos que puedan competir, con libertad y lealmente, por el favor de los usuarios libres y bien informados" (Palacios Mejía, 1999: 155-156).

En este contexto, el Derecho Privado y la Justicia Ordinaria estaban llamados a ocupar un papel estelar dentro del funcionamiento del esquema, cobrando así el protagonismo que en otra época correspondió al Derecho Administrativo y al Juez Contencioso Administrativo ${ }^{8}$. Con el fin de asegurar que los distintos operadores (públicos, privados y mixtos) participantes en el mercado de servicios públicos puedan competir en condiciones de igualdad, la Ley 142 de 1994 (en adelante LSPD) establece un régimen jurídico único aplicable por igual a todos los sujetos prestadores. Este régimen abarca tanto lo

6 Aunque a día de hoy superado gracias a la nueva concepción del Derecho Administrativo que ha normalizado la aplicación de normas de Derecho Privado a las actuaciones de la Administración (cfr. SCHMIDT-ASSMANN, 2003: 293 y ss.), especialmente durante la década de 1990 fue frecuente hablar de este fenómeno, producto de la recurrente y hasta entonces inusual aplicación a las actuaciones de la administración de procedimientos de derecho privado, el cual pasaba a convertirse "en un cauce normal para el ejercicio de no pocas funciones públicas". Cfr. MARTIN-Retortillo Baquer (1996: 212). En la doctrina colombiana, se ocupa de este asunto, entre otros, MARín CORTÉS (2008: 227-228).

7 Consejo de Estado, Sala de lo Contencioso Administrativo, Sección Tercera, Sentencia AP 1470 de 2005.

8 Vid. JèZE (s.f.: 80 y ss.). 
relativo a los actos y contratos de las empresas, como a sus relaciones con los usuarios y a la sujeción de los operadores a la regulación y a la inspección, vigilancia y control de las autoridades competentes.

De aquí que, con independencia de su naturaleza (pública, privada o mixta) se prevea a la empresa de servicios públicos (ESP) -sociedades por acciones cuyo objeto es la prestación de los servicios públicos (art. 17 LSPD)-como la principal forma de organización propia del esquema impuesto. Además, de acuerdo con distintas disposiciones de la LSPD, el Derecho Privado es, sin distinción, el régimen aplicable a los actos y contratos de los prestadores de servicios públicos. El artículo 32 LSPD desarrolla esta lógica y en relación con el régimen jurídico aplicable a los actos de las ESP, prescribe:

(...) los actos de todas las empresas de servicios públicos, así como los requeridos para la administración y el ejercicio de los derechos de todas las personas que sean socias de ellas, en lo no dispuesto en esta Ley, se regirán exclusivamente por las reglas del derecho privado.

Siendo esto así, tratándose de actos sometidos por regla general al Derecho Privado y al ser inaplicable el artículo 75 de la Ley 80 de 1993, que fundamenta la competencia de la justicia administrativa sobre los contratos estatales, a falta de una cláusula especial que disponga lo contrario, el juez de conocimiento de las controversias sobre actos, hechos y contratos de las ESP públicas, privadas y mixtas, de manera indistinta, será la justicia ordinaria. El conocimiento por parte del juez administrativo de las controversias en materia de servicios públicos pasó así de ser la regla general a ser la excepción.

A pesar de lo que estas declaraciones generales del legislador permitirían augurar y a lo que se podría desprender de la contractualización de la relación entre "la empresa" de servicios públicos y el usuario ${ }^{9}$, así como de la lógica privatizadora, liberalizante y empresarial que inspiró el cambio de modelo impulsado por la legislación ${ }^{10}$, el desarrollo que hoy se percibe es muy distinto del que quizás se pudo vislumbrar hace 20 años, cuando se expidió la LSPD; al punto de constituir, puede afirmarse, un desarrollo en sentido contrario del que entonces se pudo avizorar. La lectura atenta y no ideológica que de su articulado han hecho la jurisprudencia y la doctrina ha sido la clave de este desarrollo.

En efecto, ha sido el examen exhaustivo del texto legal el que ha permitido a la jurisprudencia esclarecer la naturaleza mixta del régimen normativo instaurado por la LSPD y afirmar que "pese a la insistencia de la ley en el sentido de que los actos y contratos de todas las empresas de servicios públicos domiciliarios estarán sometidos al derecho privado, la realidad que muestra la interpretación armónica de la ley en concordancia con la Carta es otra"11.

9 Para autores como PALACiOs Mejía, dado que en estos contratos no se pueden introducir cláusulas excepcionales, ellos originan "una típica relación comercial, como la que existe entre un transportador o un banquero y sus clientes". Vid. PAlacios Mejía (Op. cit: 164).

10 Sobre la visión económica de los servicios públicos, véase ArIÑO OrTIZ (2003).

11 Consejo de Estado, Sala Plena de lo Contencioso Administrativo, auto del 23 de septiembre de 1997, Exp. S-701. 
Este postulado, oportunamente defendido por la jurisprudencia y por la doctrina ha puesto de relieve las particularidades del régimen jurídico de los servicios públicos, y en especial la enorme responsabilidad social y jurídica que tienen los operadores frente a los usuarios, las autoridades y a la comunidad en general, así como las facultades especiales que les reconoce la ley (cualquiera que sea la naturaleza del prestador) como "privilegios indispensables para garantizar su funcionamiento y permitirles, además, la prestación de dichos servicios de manera continua, eficiente y eficaz"12.

De acuerdo con la interpretación que han hecho la doctrina y la jurisprudencia del texto de la LSPD, la intervención del contencioso administrativo requiere bien de una expresa cláusula legal que otorgue dicha competencia, o bien de un enunciado legal que revista al operador de prerrogativas de poder público ${ }^{13}$. Dado el carácter de reserva legal que constitucionalmente se ha dado a la regulación de los procesos judiciales y a las reglas de competencia de la jurisdicción ${ }^{14}$, la presencia de una disposición legal expresa que atribuya el conocimiento de un determinado asunto al contencioso despeja cualquier duda que se pueda tener al respecto. Es lo que ocurre, por ejemplo, con las controversias relacionadas con los contratos en los que se haya incluido cláusulas exorbitantes (art. 31 LSPD) o con los contratos de concesión para el uso de recursos naturales o del espectro electromagnético (art. 39.1 LSPC).También es el caso de las decisiones que se adoptan en ejercicio de los derechos y prerrogativas que se confiere a las ESP para el uso del espacio público, la ocupación temporal de inmuebles y para promover la constitución de servidumbres o la enajenación forzosa de los bienes que se requiera para la prestación del servicio (art. 33 LSPD).

12 Corte Constitucional, sentencia T-270 de 2004. En sentido análogo, véase la sentencia C-263 de 1996 o C-451 de 1999. Del Consejo de Estado, cfr.de la Sección Tercera de la Sala de lo Contencioso Administrativo, entre otras, las sentencias AP-254 de 2005 y AG-016 de 2011.

13 De acuerdo con lo expresado por la Sala Plena del Consejo de Estado en el auto de 23 de septiembre de 1997 (S-701), "[1]os actos y contratos de las empresas de servicios domiciliarios son privados y están sometidos, por regla general, al derecho privado y sus conflictos son dirimibles ante la jurisdicción ordinaria. b)No obstante esto, las citadas empresas pueden dictar ciertos actos administrativos, susceptibles de recursos y de acciones contencioso administrativas, entre los que puedan citarse los de negativa a celebrar el contrato de servicios públicos, los que ordenan su suspensión o terminación o deciden el corte del servicio y su facturación (art 154 inc $1^{\circ}$ ). c) Asimismo, esas empresas pueden celebrar contratos sometidos por regla general al derecho privado y a la jurisdicción ordinaria $;$ y otros, como los de prestación de servicios regulados en los arts. 128 y ss. y los demás contratos que contengan cláusulas exorbitantes por imposición o autorización de las Comisiones de Regulación, en los cuales el derecho público será predominante y cuyas controversias serán de la jurisdicción administrativa (art. 31 inc $2^{\circ}$ ), porque quien presta esos servicios se convierte en copartícipe, por colaboración, de la gestión estatal; $\mathrm{o}$, en otras palabras, cumple actividades o funciones administrativas. d) El ejercicio de las facultades previstas en los arts. 33,56,57, 116, 117 y 118 de la ley 142, dará lugar a la expedición de actos controlables por la jurisdicción administrativa, y e) Los contratos especiales enunciados en el art 39 de la mencionada ley estarán sujetos al derecho privado, salvo el señalado en el art 39.1 que estará sometido al derecho público y a la jurisdicción administrativa". Cfr. SAnTOfimio Gamboa (2004: 101 y ss.).

14 Artículos 29 y 89 de la Constitución. Cfr., entre otras, la Sentencia C-319 de 2013 de la Corte Constitucional. 
Sin embargo, no en todos los eventos en los que el legislador otorgó alguna prerrogativa a los operadores estableció de forma expresa la sujeción de lo resuelto al control del contencioso. Es lo que ocurre, por ejemplo, con las controversias relacionadas con el contrato de condiciones uniformes (relación empresa-usuario). El carácter mixto, de este contrato, con un fuerte componente de Derecho Público que busca corregir el desequilibrio contractual que resulta de la posición dominante del prestador, justifica la intervención del juez administrativo ${ }^{15}$. De igual manera, el contrato que celebra una entidad territorial con una empresa de servicios públicos con el objeto de que asuma la prestación de uno o varios servicios públicos domiciliarios o sustituya en la prestación a otra empresa que entre en causal de disolución o liquidación, caso en el cual, conforme a lo previsto por el parágrafo del artículo 31 de la LSPD (introducido por el art. 3 de la Ley 689 de 2001), aplican las reglas del Estatuto de Contratación Estatal y, por ende, se activa la cláusula de competencia del contencioso prevista por el artículo 75 de la Ley 80 de 1993. También sucede con las atribuciones concedidas por los artículos 56 y 57 (que declaran de utilidad pública e interés social la ejecución de obras para prestar los servicios públicos y la adquisición de predios para garantizar la protección de las instalaciones respectivas y faculta a las ESP para imponer servidumbres, hacer ocupaciones temporales y remover obstáculos), 140 y 141 (atinentes a la terminación, suspensión y corte del servicio) y 152 a 159 (que establecen el procedimiento administrativo especial de defensa del usuario en sede de la empresa). En estos eventos, pese a la ausencia de una disposición expresa que fundamente la competencia de la justicia administrativa, la jurisprudencia ha entendido que la ley revistió al prestador del servicio de prerrogativas propias de las autoridades públicas y, por lo mismo, los actos en los que se concretan han de estar sujetos al control propio de esta clase de determinaciones ${ }^{16}$. En últimas, como ha destacado la doctrina, "[q]ue el derecho permita que un sujeto se imponga (declaración de poder) frente a otro u otros es indiscutiblemente la contemplación jurídica de una imposición de voluntad; una imposición que rompe con la generalidad jurídica o cuando menos con aquella del derecho privado y fuerza a que su análisis sea objeto de estudio del derecho público" (Montaña Plata, 2005: 197).

Ahora bien, este ámbito competencial restringido y delineado por la LSPD sería ensanchado años más tarde por la Ley 446 de 1998, en cuyos artículos 40 y 42 (modificatorios de los arts. 132 y $134 \mathrm{~B}$ del CCA) se estableció el conocimiento de los conflictos originados en contratos celebrados por entidades prestadoras de servicios públicos cuya finalidad estuviera vinculada con la prestación del servicio público domiciliario. Esta competencia, con todo, no ha sido pacífica, pues la jurisprudencia de la Sección

15 Vid. Consejo de Estado, Sala Plena de lo Contencioso Administrativo, auto del 23 de septiembre de 1997, Rad. S-701; o también, de la Corte Constitucional, las sentencias C-263 de 1996 y C-558 de 2001.

16 Consejo de Estado, Sala Plena de lo Contencioso Administrativo, auto del 23 de septiembre de 1997, Exp. n. ${ }^{\circ}$ S-701. En este orden, tal como manifiesta ATEhortúa Ríos (2006: 46), "[n]o toda actuación del proveedor de los servicios lleva implícita la función pública. Únicamente cuando, en desarrollo de la ley, ejerce un acto de autoridad o coloca al usuario en relación de subordinación, nos encontramos en presencia de este tipo de actuación". 
Tercera del Consejo de Estado ha oscilado entre la defensa de la aplicación ${ }^{17}$ de estas disposiciones y la supuesta derogación por la ley 489 de $1998^{18}$. Lo anterior, sin contar con que esta ley dispuso en su artículo 164 que las competencias allí previstas sólo entrarían a regir cuando empezaran a funcionar los juzgados administrativos; precepto que sería modificado por la Ley 954 de 2005, por medio de la cual se modifican y adicionan algunas normas de la Ley 446 de 1998, que dispuso la entrada en vigor de las disposiciones sobre competencia previstas en la Ley 446, que se encontraban suspendidas.

La incertidumbre jurídica ocasionada por este debate jurisprudencial llevaría a que en 2006, mediante la Ley 1107, se reformara nuevamente lo relativo al conocimiento de las controversias en materia de servicios públicos. Esta normativa, cuyo artículo $1^{\circ}$ modificó el artículo 82 del CCA ${ }^{19}$, adoptó un criterio subjetivo u orgánico como determinante de la competencia de la jurisdicción ${ }^{20}$ y supuso un nuevo alargamiento del radio de cobertura del contencioso en materia de servicios públicos. Esto, fundamentalmente, por cuanto cifró el objeto de la jurisdicción en "juzgar las controversias y litigios originados en la actividad de las entidades públicas" (en lugar de "juzgar las controversias y litigios

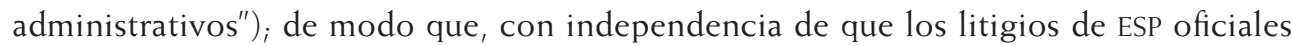
tuvieran o no origen en un contrato directamente vinculado con la prestación del servicio o de que presentara cláusulas excepcionales o que hicieran relación a alguno de los actos mencionados por la ley como expresión de un poder público, su juzgamiento pasó a ser incondicionadamente competencia del contencioso administrativo ${ }^{21}$.

El CPACA parece transitar por la misma senda, aunque el panorama no es del todo claro, ya que en su artículo 104 adopta una suerte de criterio mixto, que combina un

17 Consejo de Estado, Sala de lo Contencioso Administrativo, Sección Tercera, auto del 8 de febrero de 2001, Exp. n. ${ }^{\circ}$ 16661. De esta misma Corporación, los autos de 6 de junio de 2002, Exp. 20634, y del 21 de junio de 2002, Exp. 20825.

18 Consejo de Estado, Sala de lo Contencioso Administrativo, Sección Tercera, auto del 12 de agosto de 1999, Exp. n. ${ }^{\circ} 1646$.

19 Artículo $1^{\circ}$. El artículo 82 del Código Contencioso Administrativo modificado por el artículo 30 de la Ley 446 de 1998, quedaría así:

"Artículo 82. Objeto de la jurisdicción de lo contencioso administrativo. La jurisdicción de lo contencioso administrativo está instituida para juzgar las controversias y litigios originados en la actividad de las entidades públicas incluidas las sociedades de economía mixta con capital público superior al $50 \%$ y de las personas privadas que desempeñen funciones propias de los distintos órganos del Estado. Se ejerce por el Consejo de Estado, los tribunales administrativos y los juzgados administrativos de conformidad con la Constitución y la ley. // Esta jurisdicción podrá juzgar, inclusive, las controversias que se originen en actos políticos o de Gobierno. // La jurisdicción de lo contencioso administrativo no juzga las decisiones proferidas en juicios de policía regulados especialmente por la ley. Las decisiones jurisdiccionales adoptadas por las Salas Jurisdiccionales Disciplinarias del Consejo Superior de la Judicatura y de los Consejos Seccionales de la Judicatura, no tendrán control jurisdiccional".

20 Vid. Gil Botero (2014: 54-55).

21 Cfr. Consejo de Estado, Sala de lo Contencioso Administrativo, Sección Tercera, auto del 8 de febrero de 2007, Exp. 05001-23-31-000-1997-02637-01(30903). En sentido similar, de la misma Corporación, el auto del 18 de julio de 2007, Rad. n. ${ }^{\circ}$ 25000-23-26-000-1999-00155-01(29745). 
criterio material-normativo difícil de precisar con la atribución legal directa de ciertos asuntos y el criterio orgánico acogido por la Ley 1107 de $2006^{22}$. En efecto, la reforma de 2011 confía al contencioso el juzgamiento de "las controversias y litigios originados en actos, contratos, hechos, omisiones y operaciones, sujetos al derecho administrativo, en los que estén involucradas las entidades públicas o los particulares cuando ejerzan función administrativa" (art. 104). Luego, en su numeral $3^{\circ}$, expresamente señala que le corresponde conocer de los conflictos "relativos a contratos celebrados por cualquier entidad prestadora de servicios públicos domiciliarios en los cuales se incluyan o hayan debido incluirse cláusulas exorbitantes". Por último, en el parágrafo agrega que "[p]ara los solos efectos de este Código, se entiende por entidad pública todo órgano, organismo o entidad estatal, con independencia de su denominación, las sociedades o empresas en las que el Estado tenga una participación igual o superior al $50 \%$ de su capital; y los entes con aportes o participación estatal igual o superior al 50\%". El análisis conjunto de estas disposiciones permite concluir que, bajo el régimen del CPACA, todas las controversias contractuales de ESP oficiales y mixtas (con aporte estatal superior al 50\%) serán de conocimiento de la justicia administrativa $;$ y que su competencia se activará siempre, con independencia de la naturaleza pública, privada o mixta del operador, allí donde se tiene un conflicto originado en un contrato en el cual se pactaron cláusulas exorbitantes. Una situación, en suma, que ratifica la tendencia a devolver al contencioso administrativo el conocimiento de un numero importante de controversias en este campo, pese a tratarse hoy en día el servicio público de una actividad sujeta mayoritariamente al Derecho Privado.

\section{PANORAMA GLOBAL DE LA COMPETENCIA DEL CONTENCIOSO ADMINISTRATIVO EN EL ÁMBITO DE LOS SERVICIOS PÚBLICOS}

Aun cuando el recorrido por la regulación legal de la competencia del contencioso en materia de actos y contratos de los operadores de servicios públicos permite apreciar una progresiva vuelta al contencioso, debe destacarse que su papel en el sector va mucho más allá del solo conocimiento de estos asuntos. El hecho de involucrar autoridades administrativas tradicionales, como el Presidente, las comisiones de regulación y la Superintendencia de Servicios Públicos Domiciliarios (en adelante SSPD) hace de este un ámbito en el que abundan las actuaciones de los poderes públicos sujetos a control del contencioso. Aunque en relación con varias de tales determinaciones no existe ninguna duda respecto a su carácter de actos controlables por la jurisdicción (zona de certeza), en razón de las particularidades del sector y a la lógica económica y flexibilizante impulsada por la LSPD, no son pocos los casos no exentos de controversias (zona de incertidumbre). 


\subsection{La zona de certeza competencial del contencioso administrativo en materia de servicios públicos}

Toda vez que la liberalización de los servicios públicos efectuada en 1994 no supuso la desregulación del sector sino, justamente, todo lo contrario, el fortalecimiento del papel del Estado como regulador y órgano de vigilancia y control de los actores que compiten en él, el modelo impuesto no ha implicado una marginación de las autoridades públicas ni, por lo tanto, del contencioso administrativo en tanto que juez de los actos de poder público. Así lo permite corroborar la lectura de la copiosa jurisprudencia expedida por el Consejo de Estado a propósito de las numerosas controversias originadas en esta clase de actos proferidos por las distintas autoridades involucradas en el sector: Decretos gubernamentales de distinto tipo, decisiones adoptadas por las comisiones en ejercicio de su función de regulación, resoluciones sancionatorias, actos que decretan áreas de servicio exclusivo o fijan el valor de tasas a pagar por los operadores son algunos de los casos más frecuentes que llegan a conocimiento de la jurisdicción. En mayor o menor medida, se trata de actos en relación con los cuales su control por el contencioso resulta pacífico.

Un primer grupo de asuntos lo integran las decisiones adoptadas por el Presidente en ejercicio de sus funciones constitucionales. En efecto, se tiene que en su papel natural de órgano de control de los actos de la Administración, el contencioso se ha ocupado de la fiscalización de los actos de reglamentación de la ley expedidos por el Presidente, a quien, por mandato constitucional, corresponde la reglamentación de la legislación en materia de servicios públicos, esto es, la expedición de los reglamentos ejecutivos necesarios para hacer posible su pleno acatamiento y aplicación en el sector (art. 189.11 de la Constitución). También le incumbe la determinación de la estructura de los ministerios, departamentos administrativos y demás organismos de la Administración Pública Nacional con sujeción a los principios y criterios establecidos en la ley (art. 189.16 de la Constitución), aspecto igualmente relevante para el sector.

Así, en lo tocante al ejercicio de la facultad reglamentaria de la ley, se tiene que el Consejo de Estado ha hecho valer los límites que tradicionalmente enmarcan el ejercicio de esta facultad gubernamental. El fallo de 27 de octubre de 2005 de la Sección Tercera ofrece un ejemplo de ello frente a un decreto expedido en materia de servicio de aseo $^{23}$. Por encontrar que el decreto demandado (reglamentario de la Ley 632 de 2000) desbordó el marco de legalidad impuesto por la norma a reglamentar (el art. 9 de la Ley 632), decretó parcialmente su nulidad, pues consideró que, además de no ser necesaria la reglamentación de dicho precepto, el reglamento demandado modificó la literalidad de otra de las disposiciones prevista en aquella cuando varió la definición legal del servicio de aseo.

De otro lado, y en relación con el poder de reforma de la estructura de los órganos administrativos presentes en el sector, se tiene el caso de la sentencia de 6 de agosto de

23 Consejo de Estado, Sala de lo Contencioso Administrativo, Sección Tercera, sentencia del 27 de octubre de 2005, Rad. n. ${ }^{\circ}$ 11001-03-26-000-2002-00045-01(23583). 
2004, en la cual la Sección Primera del Consejo de Estado declaró conforme a las facultades de modificación de la estructura administrativa de la CRA por haberse encontrado ajustada a los principios y reglas generales definidos por el artículo 54 de la Ley 489 de 1997.

El control judicial que ejerce el contencioso sobre las decisiones del Presidente ha llevado a que incluso se declare la nulidad de un apartado de la norma por medio de la cual el Presidente delegó sus funciones constitucionales y legales en las comisiones de regulación, por considerar que dicha delegación no cumplía con las exigencias de claridad, precisión y certeza que exigen la Constitución y la ley ${ }^{24}$.

En todos estos eventos, el indiscutible carácter de reglamento que ostentan las determinaciones que con carácter general adopta el Presidente en ejercicio de estas competencias ofrece un claro soporte al control que se ejerce sobre ellas, por lo cual se puede afirmar que, por regla general, su sujeción a la fiscalización del contencioso ha estado exenta de discusión.

Más controversial ha sido lo relativo al control de los actos de las comisiones de regulación. Al respecto se tiene que aunque inicialmente existió polémica sobre su naturaleza y sobre la calidad de sus actos dada su condición (más teórica que constitucional) de autoridades independientes, tempranamente la Corte Constitucional dejó en claro que la función reguladora no tenía rango de ley pues envolvía una atribución administrativa encomendada por la Constitución al Presidente, para que la ejerciera de conformidad con la ley y los reglamentos, y que, por lo tanto, sus decisiones eran susceptibles del control por parte del contencioso administrativo ${ }^{25}$. El sometimiento de las decisiones regulatorias de las comisiones de regulación al contencioso administrativo ha sido reafirmado por esta Corporación, que en su jurisprudencia ha señalado que ellas no son expresión de la función legislativa ni buscan completar ni suplir los vacíos de la ley, sino que son una manifestación de la función administrativa y, más concretamente, de la función de policía que el Estado se reserva en materia de servicios públicos ${ }^{26}$. De aquí que

24 Consejo de Estado, Sala de lo Contencioso Administrativo, Sección Primera, sentencia de 15 de noviembre de 2011, Rad. n. ${ }^{\circ} 110010324000200300395$ 01. En este fallo, se valoró la validez de un apartado del artículo 1. ${ }^{\circ}$ del Decreto n. ${ }^{\circ} 1524$ de 1994, "por el cual se delegan funciones presidenciales de señalar políticas generales de administración y control de eficiencia en los servicios públicos domiciliarios, y se dictan otras disposiciones", y se consideró que debía ser anulado, por cuanto al delegar las facultades que le otorga el artículo 68 LSPD "y las disposiciones concordantes," el artículo $1^{\circ}$ del Decreto 1524 de 1994 por la falta de precisión y concreción de la frase"infringió las normas en que debió sustentarse (art. 84 del CCA), porque la Carta en sus artículos 209, 211, 365 y 370 establece la mecánica del ejercicio de funciones referentes al servicio público y de delegación de funciones, y la Ley 142 de 1994 señaló las funciones delegables por el Presidente, especialmente en su Artículo 68. Pero con la delegación de funciones a manera de "disposiciones concordantes" de la Ley 142 de 1994, asigna una cláusula general de competencia a favor de las comisiones de regulación que contraviene todas las disposiciones anteriormente citadas y desbordó el alcance de la autorización de delegación allí prevista".

25 De acuerdo con lo expresado por la Corte Constitucional en la sentencia C-1 162 de 2000: "[e]s importante resaltar que contra los actos y decisiones de las comisiones caben los recursos previstos en la ley para los actos administrativos".

26 Consejo de Estado, Sala de lo Contencioso Administrativo, Sección Tercera, sentencia del 5 de marzo de 2008, Rad. n. ${ }^{\circ}$ 1001-03-26-000-2001-0029-01 (20.409). En sentido similar, de la Sección 
se haya enfatizado que su función no les permite suplantar o reemplazar al legislador ni reglamentar directamente la ley, puesto que sus facultades regulatorias deben cumplirse conforme a lo previsto en la Constitución, la ley y los reglamentos ${ }^{27}$.

Con base en estas consideraciones, el Consejo de Estado ha declarado, por ejemplo, la nulidad de algunas disposiciones de una resolución de la CRA en la que se entraba a reglamentar la Ley 142 de 1994, excediéndose en el ámbito de sus competencias. Por esta razón, se consideró que "tal desarrollo de la norma legal es propio de la potestad reglamentaria del Presidente de la República y, por el contrario, no hace parte de las facultades y competencias atribuidas a las distintas comisiones de regulación ${ }^{\prime 28}$.

Otra clase de desbordamiento de las funciones de las comisiones de regulación que también ha dado lugar a la anulación de las resoluciones de estos órganos es la adopción de decisiones en contravía de lo establecido en la ley. Así, por ejemplo, en fallo de 2 de mayo de 2007 la Sección Tercera del Consejo de Estado anuló un apartado de una resolución de la CREG que establecía una restricción para participar en los procesos de selección allí regulados de forma contraria a lo previsto por la Ley 143 de 1994, en tanto imponía como exigencia que el proponente -sin distingo alguno- tuviera como objeto exclusivo la actividad de transmisión nacional en lo relacionado con el sector eléctrico, desconociendo que el legislador había limitado este requisito a los operadores constituidos después de su entrada en vigencia ${ }^{29}$.

La sujeción de la regulación al bloque de legalidad también se ha hecho valer en otros supuestos en los cuales se han transgredido principios como el de la prohibición de irretroactividad de las normas, como en el caso del fallo de 21 de agosto de 2008, en el que se anuló un apartado de una resolución de la CRC que buscaba dar efectos desde el 1 de enero de 2002 a una resolución expedida el 12 de abril de ese año ${ }^{30}$.

Primera de esta misma Corporación, la sentencia de 30 de abril de 2009, Rad. n. ${ }^{\circ} 100103240002004$ 0012301

27 Consejo de Estado, Sala de lo Contencioso Administrativo, Sección Tercera, sentencia del 5 de marzo de 2008, Rad. n. ${ }^{\circ} 1$ 1001-03-26-000-2001-0029-01 (20.409).

28 Ídem. Otro caso en el que se adoptó una decisión similar lo ofrece el fallo de 30 de abril de 2009 de la Sección Primera del Consejo de Estado, Rad. n. ${ }^{\circ} 10010324000200400123$ 01, en el que se declaró la nulidad de la Resolución 245 de 22 de Abril de 2003, proferida por la Comisión de Regulación de Agua Potable y Saneamiento Básico - CRA, "por la cual se regulan los numerales 73.8 y 73.9 del artículo 73 de la Ley 142 de 1994 en relación con la solución de los conflictos que surjan entre las empresas de servicios públicos de acueducto, alcantarillado y aseo", por considerar que aunque la LSPD reviste a las comisiones de regulación de las potestades normativas necesarias para cumplir dicha función "en ningún momento les está atribuyendo la facultad para ejercer potestades reglamentarias en reemplazo del Presidente de la República. La facultad de regulación allí mencionada, ha de entenderse entonces en el sentido técnico-económico que se mencionó en las páginas precedentes, esto es, como potestad para promover la competencia, corregir las fallas del mercado y garantizar la libertad de empresa y la libre concurrencia, de conformidad con lo dispuesto en las normas constitucionales relativas a la intervención del Estado en el ámbito de los servicios públicos".

29 Consejo de Estado, Sala de lo Contencioso Administrativo, Sección Tercera, sentencia del 2 de mayo de 2007, Rad. n. ${ }^{\circ}$ 11001-03-26-000-1998-05354-01(16257).

30 Consejo de Estado, Sala de lo Contencioso Administrativo, Sección Primera, sentencia del 21 de agosto de 2008, Rad. n. ${ }^{\circ}$ 11001-03-24-000-2003-00047-00. 
Otro ejemplo de esta subordinación a la legalidad y de su control por el contencioso administrativo lo ofrece el fallo de 16 de febrero de 2012, en el que se declaró la nulidad de una disposición de una resolución de la CREG en la que, so pretexto de regular unos ingresos de actores del mercado, se reglamentaban los honorarios por defensa judicial asociados con demandas instauradas por agentes del mercado. El fundamento de la nulidad fue la falta de competencia de la CREG para imponer como Ingresos Regulados por concepto de servicios presuntamente prestados por el Centro Nacional de Despacho (CND), el Administrador del Sistema de Intercambios Comerciales del Mercado de Energía Mayorista (ASIC) o el Liquidador de los Intercambios Comerciales del Sistema Interconectado del sector eléctrico(LAC) los honorarios por defensa judicial a que haya lugar por aplicación por parte de esas dependencias de la reglamentación vigente, puesto que no guarda "relación directa e inescindible" con los servicios de despacho y coordinación que están a su cargo, toda vez que se trata de un servicio contratado por los operadores con profesionales del derecho.

Más polémico podría resultar, por su carácter cuasi-jurisdiccional, el sometimiento a la jurisdicción administrativa de los actos administrativos que resuelven las controversias entre operadores dictadas por las comisiones en ejercicio de las facultades otorgadas por los numerales $8 .^{\circ}$ y $9 .^{\circ}$ del artículo 73 LSPD. Según lo indicado por la jurisprudencia, "[s]e trata de decisiones llamadas a prevenir o corregir algunas fallas del mercado y a normalizar el buen funcionamiento y la correcta prestación de los servicios, con el objeto de encauzarlos hacia la realización de los fines que aparecen mencionados en la Constitución Política y que se precisan con mayor amplitud en el artículo $2 .^{\circ}$ de la Ley 142 de $1994^{\prime \prime 31}$. Con todo, pese a las dudas que podría suscitar el aparente contenido materialmente jurisdiccional de esta función, y por lo tanto su correlativa imposibilidad de ser revisado por un juez distinto al que tenga la calidad de superior jerárquico del órgano decisor, el propio legislador determinó en su artículo 73.8 LSPD que se trata de actos administrativos y que las decisiones así adoptadas están sujetas al control judicial, con lo cual cualquier discusión al respecto queda excluida. Ahora, debe destacarse igualmente que para la jurisprudencia constitucional se trata de actos administrativos emitidos en desarrollo de la función de regulación, con lo cual se refuerza el planteamiento legal y despeja cualquier duda al respecto ${ }^{32}$.

De otro lado, en lo que tiene que ver con las decisiones de la SSPD, cuyo papel está orientado principalmente a la protección del usuario, a asegurar el cumplimiento de la regulación y de la normatividad aplicable al sector, a evaluar la gestión de los prestadores y a tomar posesión de las empresas respectivas en ciertos casos excepcionales, se tiene que en tanto que expresión inequívoca de la tradicional función de policía administrativa el control de sus actos no ha resultado controversial. El contencioso administrativo ha

31 Consejo de Estado, Sala de lo Contencioso Administrativo, Sección Primera, sentencia del 30 de abril de 2009, Rad. n. ${ }^{\circ} 11001032400020040012301$.

32 Vid. Corte Constitucional, sentencia C-1120 de 2005. 
fiscalizado así las decisiones adoptadas en ejercicio de sus funciones sancionatorias y pese a la indeterminación del enunciado legal que fundamenta dicha competencia (que abre un amplio margen de discrecionalidad en cabeza del operador administrativo) ha validado su facultad para abrir investigaciones y sancionar las conductas que se apartan de "las leyes y actos administrativos a los que estén sujetos quienes presten servicios públicos, en cuanto el cumplimiento afecte en forma directa e inmediata a usuarios determinados ${ }^{\prime \prime 3}$. Incluso ha manifestado recientemente, a propósito del incumplimiento de un operador de telecomunicaciones de su obligación de información de manera oportuna y veraz a la SSPD, que "los actos realizados por las empresas prestadoras pueden o no afectar directa e inmediatamente a usuarios determinados del servicio público domiciliario, en tanto la facultad de investigar y sancionar procede cuando se han desconocido las disposiciones legales o reglamentarias" ${ }^{\prime 34}$.

También han sido objeto de verificación el respeto al límite temporal de 3 años impuesto a la facultad sancionatoria por la ley procesal administrativa como condicionante a la competencia temporal de la entidad y la observancia del debido proceso en los trámites sustanciados ${ }^{35}$. Sobre este último aspecto incluso ha considerado conforme al debido proceso y a los principios de celeridad, economía e igualdad acumular de oficio en un mismo expediente las actuaciones que tengan el mismo efecto y una relación íntima cuando con la acumulación se puedan evitar decisiones contradictorias. Este aspecto resulta determinante en el ámbito de la protección a usuarios, dado el carácter masivo de los servicios que se prestan y de la multitud de personas que pueden resultar afectadas por una misma conducta de los operadores ${ }^{36}$. La preocupación por la plena garantía del debido proceso en esta clase de actuaciones de la SSPD ha llevado a que también se examine con detalle la dosificación de las sanciones impuestas y que se considere, como en el caso del fallo del 21 de agosto de 2014 de la multa impuesta a un operador de telefonía por un incremento en las tarifas por encima del IPC, que la misma resultaba razonable y proporcionada en atención a que había afectado al sector más vulnerable de la población ${ }^{37}$.

33 Cfr. Consejo de Estado, Sala de lo Contencioso Administrativo, Sección Primera, sentencia del 28 de agosto de 2014, Rad. n. ${ }^{\circ} 250002324000200800369$ 01. También, de esta misma Corporación, la sentencia del 22 de septiembre de 2012, Rad. n. ${ }^{\circ}$ 25000-23-24-000-1996-06880-01.

34 Consejo de Estado, Sala de lo Contencioso Administrativo, Sección Primera, sentencia del 21 de agosto de 2014, Rad. n. ${ }^{\circ}$ 25000-23-24-000-2008-00236-01.

35 Consejo de Estado, Sala de lo Contencioso Administrativo, Sección Primera, sentencia del 23 de febrero de 2012, Rad. n. ${ }^{\circ}$ 2004-00344.

36 Consejo de Estado, Sala de lo Contencioso Administrativo, sentencia del 4 de agosto de 2011, Rad. n. ${ }^{\circ}$ 25000-23-24-000-2003-01151-01. De la misma Corporación, véase también la sentencia del 5 de junio de 2014, Rad. n. ${ }^{\circ}$ 25000-23-24-000-2003-01130-01.

37 Consejo de Estado, Sala de lo Contencioso Administrativo, Sección Primera, sentencia del 21 de agosto de 2014, Rad. n. ${ }^{\circ}$ 25000-23-24-000-2008-00350-01. 


\subsection{La zona de incertidumbre competencial del contencioso administrativo en materia de servicios públicos}

Además de asumir la fiscalización de los actos de poder público emanados de las autoridades que integran el sector, en relación con los cuales parece indiscutible su sujeción al control de la jurisdicción contencioso administrativa, ella también ha avocado conocimiento de controversias en relación con las cuales, por distintas razones, la competencia del juez administrativo podría resultar debatible. Dos grandes bloques de decisiones podrían incluirse aquí: las denominadas medidas de mercado y las decisiones adoptadas por las empresas frente a los usuarios en sede de la empresa.

En relación con el primer grupo, esto es, con las denominadas medidas de mercado, debe destacarse que su sometimiento al control judicial, propio de las reglas de Derecho, podría llegar a cuestionarse si se pone de relieve (como lo hacen algunos prestadores de servicios) su esencia y lógica fundamentalmente económicas. De acuerdo con la comprensión que se tiene de ellas, son reglas adoptadas por los reguladores para crear incentivos o desincentivos frente a determinadas conductas de los operadores del mercado. Por eso no se toman como reglas prohibitivas o como penalidades en estricto sentido, pues más que reprochar una conducta indebida o ilícita suponen simplemente una respuesta frente al comportamiento asumido: la asunción por el operador de la consecuencia prevista por la realización de la conducta que se busca desincentivar.

Pese a su carácter esencialmente económico, la jurisprudencia administrativa las ha reconocido como parte de los instrumentos de regulación con que cuentan las autoridades y se ha pronunciado sobre ellas ${ }^{38}$. Ha dicho así, por ejemplo, que son medidas reguladoras de conducta, "no son sanciones propiamente dichas, sino reglas para la efectividad de los derechos y obligaciones de los sujetos o partes del contrato de suministro de energía, y, por tanto, para la ejecución del mismo y la aplicación de las consecuencias del incumplimiento o mora por parte de los comercializadores y /o distribuidores" ${ }^{\prime 39}$. Y agregó que "[m]ás que la tipificación de faltas administrativas, de sanciones y de procedimiento administrativo sancionatorio, lo que se incluye en la resolución son reglas atinentes a las relaciones jurídicas propias del contrato de suministro de energía, por consiguiente, no se opone a las disposiciones legales que prevén sanciones y procedimientos por faltas administrativas en materia de servicios públicos". De modo que, con independencia de su carácter esencialmente económico, tienen un componente jurídico que no puede ser desconocido. Y al margen de si pueden dar lugar o no a la imposición de sanciones por

38 Debe tenerse presente que según la jurisprudencia la amplitud de responsabilidades que afronta el Estado en relación con la dirección del sistema económico implica considerar que "el vocablo "regulación" adquiere (...) una connotación mucho más dilatada y omnicomprensiva que desborda el mero concepto de producción normativa, para abarcar o comprender también, con mayor amplitud, la intervención orientada a corregir las fallas del mercado". Cfr. Consejo de Estado, Sala de lo Contencioso Administrativo, Sección Primera, sentencia del 30 de abril de 2009, Rad. n. ${ }^{\circ} 11001032400020040012301$

39 Consejo de Estado, Sala de lo Contencioso Administrativo, Sección Primera, sentencia del 17 de agosto de 2000, Rad. n. 5920. 
parte del órgano de vigilancia y control (cuestión que todavía no ha sido resuelta por la jurisdicción y en relación con la cual no resulta procedente adelantar ningún juicio), es claro que su sometimiento al bloque de legalidad es pleno.

Por esta razón, la jurisprudencia ha examinado tanto su aspecto formal como sustancial. Así, por ejemplo, en la sentencia del 23 de agosto de 2012, ante el cargo de nulidad de una resolución con base en el supuesto vicio de forma que resulta de haber omitido la CREG el concepto previo no vinculante del Consejo Nacional de Operación, por constituir ellas parte del Reglamento de Operación, se sostuvo que

En el caso de las resoluciones demandadas, no se trataba de regular el planeamiento y la coordinación de la operación del Sistema Interconectado Nacional, sino de establecer condiciones de mercado que permitieran el desarrollo de la libre competencia entre los actores del mercado mayorista de energía (...) Por lo anterior es claro para la Sala que no solo no se requería oír el concepto del Consejo Nacional de Operación, sino que existían facultades que permitían a la CREG expedir las normas demandadas y en consecuencia el cargo no prospera ${ }^{40}$.

Igualmente, pero ya desde una perspectiva sustancial, este mismo fallo admite que el órgano de regulación pueda adoptar decisiones con base en las cuales se pueden derivar consecuencias patrimoniales (responsabilidad) de la conducta de un operador del mercado. Es el caso de la Resolución CREG-034 de 2001, que prescribe:

Si el precio de oferta de un generador supera el Costo del Primer Segmento de Racionamiento, su Disponibilidad se tomará como cero (o). En caso que el CND hubiere requerido la unidad y/o planta de generación para cubrir una generación de seguridad, y el generador no haya podido justificar debidamente su oferta ante las autoridades competentes, el agente será responsable por los perjuicios derivados del racionamiento causado. Sin perjuicio de que la Superintendencia de Servicios Públicos Domiciliarios pueda tomar posesión de la empresa, de conformidad con el artículo 59.1 de la Ley 142 de 1994.

Cuando un generador declare para el despacho horario una disponibilidad igual a cero (0) y su precio de oferta sea inferior al Costo del Primer Segmento de Racionamiento y la unidad y/o planta de generación sea requerida por el CNDpara cubrir una generación de seguridad, si la planta y/o unidad de generación se encuentra indisponible y las autoridades competentes determinan que su indisponibilidad no es justificada, el agente será responsable por los perjuicios derivados del racionamiento causado, sin perjuicio de que la Superintendencia de Servicios Públicos Domiciliarios pueda tomar posesión de la empresa de conformidad con el artículo 59.1 de la Ley 142 de 1994.

40 Consejo de Estado, Sala de lo Contencioso Administrativo, sentencia del 23 de agosto de 2012, Rad. n. ${ }^{\circ}$ 11001-03-24-000-2002-00070-01. 
De acuerdo con lo sostenido en el fallo en comento:

La lectura atenta de los preceptos transcritos lleva a la Sala a concluir que la norma demandada de la Resolución CREG 034 de 2001, no establece una responsabilidad nueva sino que se limita a aplicar las normas del Código Civil, al señalar que en caso de existir conductas que, a juicio de las autoridades competentes, resultan injustificadas, que provoquen un racionamiento de energía, y si dicho racionamiento causa perjuicios, éstos deben ser indemnizados por el generador responsable de la conducta dañina. Ello implica que se deben cumplir los siguientes presupuestos: (i) debe existir una conducta del generador, (ii) dicha conducta no puede ser justificada, (iii) un daño y (iv) que ese daño sea causado por la conducta del generador. // Será entonces el juez competente quien establezca en cada caso concreto la existencia o no de responsabilidad, competencia que la Resolución CREG 034 de 2001 no varía, por lo cual no es de recibo para la Sala la afirmación del actor en el sentido que el acto acusado invade o usurpa la órbita de los jueces o desconoce el principio de presunción de inocencia consagrado por el artículo 29 de la Constitución Política.

Otro caso interesante relacionado con el control de las medidas de mercado es el resuelto por la sentencia del 10 de julio de 2014, en el cual se da pleno valor a la confianza legítima depositada por un operador del sector eléctrico que firmó con la SSPD un acuerdo de mejoramiento encaminado a lograr la viabilidad financiera de la empresa y a garantizar la adecuada prestación del servicio a los usuarios de los departamentos en los que operaba (Boyacá, Casanare, Meta y Santander), en el cual se fijaron unas metas inferiores a las exigidas por la CREG con respecto al cumplimiento de los indicadores DES y FES; indicadores de calidad establecidos por la CREG para medir la duración equivalente de las interrupciones del servicio (DES) y la frecuencia equivalente de las interrupciones del servicio (FES). No obstante la suscripción de este acuerdo, la SSPD impuso una sanción al operador por considerar que estos indicadores habían sido desconocidos. Al respecto, el Consejo de Estado sostuvo que pese al carácter vinculante de estos indicadores definidos por la CREG:

(...) el Acuerdo de Mejoramiento celebrado entre EBSA y la Superintendencia, constituía en efecto una base objetiva y plausible para colegir que durante el año 2005, estaba permitida la realización de unos estándares inferiores de cumplimiento de los valores admisibles de DES y FES para los circuitos mencionados en sus cláusulas, por lo cual resulta de suyo razonable y entendible que la actora hubiese confiado de manera legítima en que la prestación del servicio de suministro de energía de conformidad con esos estándares reducidos, no daría lugar a la imposición de sanciones por haber incurrido en una falla en el servicio. Por lo mismo, el hecho de que la Superintendencia haya multado a la actora por las fallas en que incurrió en el año 2005, sin tener en cuenta los términos del Acuerdo anteriormente mencionado, lleva a colegir que al adoptar esa determinación actuó por fuera de los parámetros de la coherencia y en contravía del principio de confianza legítima". 
Ya en un caso anterior, relacionado con la reclamación en sede de acción popular por el supuesto desconocimiento del derecho de acceso a una prestación eficiente de los servicios públicos, la Sección Primera se había manifestado en relación con la tolerancia que regía el cumplimiento de tales índices, y señaló respecto a su carácter no absoluto que

(...) de conformidad con lo establecido por la Resolución 096 de 2000, proferida por la Comisión Reguladora de Energía y Gas, por medio de la cual se presentan los indicadores para la medición de la confiabilidad del servicio y se establecen las definiciones únicas de estos indicadores, se entiende que dichos conceptos no son absolutos, puesto que tienen ciertos márgenes de tolerancia, lo que implica que para acceder a las pretensiones tendrá que probarse que las interrupciones no son justificadas y que su frecuencia y duración sobrepasan los límites establecidos por la normativa vigente que regula la prestación del servicio público de energía, hechos que para este caso en concreto no fueron probados por el demandante ${ }^{41}$.

De otra parte, y en lo que tiene que ver con el segundo grupo de casos que interesa examinar dentro de esta zona de incertidumbre, están las decisiones adoptadas unilateralmente por las empresas en relación con los usuarios. Aun cuando en principio se trata de operadores que no tienen la condición de autoridades oficiales y que obran en un mercado en competencia en desarrollo de su libertad económica, el hecho de hacerlo en el marco del contrato de servicios públicos, especial como es su naturaleza (en parte convencional, pero también en parte fuertemente disciplinada por la ley, los reglamentos y la regulación del sector), ha servido de base para que el contencioso administrativo haya asimilado estas decisiones a actos de autoridad y también se haya ocupado de examinar su legalidad ${ }^{42}$.

En este sentido, homologando por completo estas decisiones a los actos de la Administración, la jurisprudencia ha examinado en ellos algunos de los elementos tradicionales que condicionan la validez de los actos administrativos, tales como la competencia y el debido proceso, y se han adoptado decisiones anulatorias con base en estos criterios. Así, por ejemplo, la Sección Primera ha evaluado la competencia de las ESP para adoptar medidas de suspensión y corte del servicio, así como para imponer multas a los usuarios que incumplen el contrato de servicios públicos. Ha concluido que aun cuando la ley ha revestido a estos sujetos de la potestad de imponer las sanciones de suspensión o corte del servicio y de exigir al suscriptor el pago de lo consumido no facturado, no hay lugar a imponer multas. Para la jurisprudencia, la falta de cobertura legal de esta clase de sanciones se traduce en la falta de competencia de las ESP para imponerlas, por lo que

41 Consejo de Estado, Sala de lo Contencioso Administrativo, Sección Primera, sentencia del 2 de noviembre de 2006, Rad. n. ${ }^{\circ}$ 20001-23-31-000-2004-00004-01(AP).

42 Esta situación ha dado lugar a que la doctrina se formule preguntas sobre si "[e]s congruente un régimen legal que parte de la premisa según la cual los servicios públicos dejaron de ser una función administrativa, pero que a la vez dota a los operadores de prerrogativas de autoridad pública en sus relaciones con el usuario final". Cfr. SÁNCHEZ LUQUE (2014: 433). 
ha anulado las medidas así impuestas ${ }^{43}$. En el mismo sentido, la falta de consideración por parte de una ESP de la garantía del debido proceso también ha dado lugar a que se anule la decisión así impuesta ${ }^{44}$.

Tal ha sido el grado de asimilación de la jurisprudencia de los actos de las ESP a los actos de la Administración que ha declarado ilegal su decisión de cobrar el costo del cobro prejurídico o judicial tanto en casos de corte o terminación del contrato (reinstalación) como de suspensión del mismo (reconexión), pese a carecer ello de sustento contractual y regulatorio para este último evento. Consecuencia de esta decisión, por considerar que conforme a la normatividad vigente en el caso de simple suspensión por no pago del servicio (art. 140 LSPD) no hay lugar al cobro prejurídico al usuario, se condenó al operador al resarcimiento de los perjuicios ocasionados a quienes resultaron afectados por dicha decisión ilegal, para lo cual se le ordenó devolver los cobros irregulares por concepto de honorarios de abogados en procesos de reconexión ilegalmente cargados a sus abonados ${ }^{45}$.

El análisis de estos casos permite apreciar las incógnitas que genera para el funcionamiento del modelo tradicional de control judicial de los actos de la Administración la aplicación de un esquema de servicios públicos pensado en clave económica, por fuera de los cánones de la doctrina clásica del service publique impulsado por la escuela de Burdeos y acogido por el Derecho Nacional antes del cambio promovido por la Constitución y por la LSPD, en el que el grueso de las actuaciones requeridas para atender las necesidades de la colectividad está a cargo de particulares que obran en desarrollo de su libertad de empresa (en aras de obtener un beneficio económico) en un mercado en el que se supone que es la libre competencia la que permitirá alcanzar los objetivos de cobertura, calidad y eficiencia en la prestación que en otro momento recayeron directamente sobre las autoridades.

\subsection{Las acciones constitucionales como catalizador de la transformación del modelo de prestación de servicios establecido en la ley}

Un último punto que se debe examinar al revisar el panorama general de la competencia del contencioso administrativo en materia de servicios públicos es el concerniente a las acciones constitucionales. Grandes protagonistas del cambio de modelo constitucional, ellas han supuesto una fuerza verdaderamente transformadora del esquema de servicios públicos propuesto

43 Consejo de Estado, Sala de lo Contencioso Administrativo, Sección Primera, sentencia del 23 de enero de 2014, Rad. n. ${ }^{\circ}$ 25000-23-24-000-2004-00633-02.

44 Consejo de Estado, Sala de lo Contencioso Administrativo, Sección Primera, sentencia del 4 de octubre de 2012, Rad. n. ${ }^{\circ}$ 2004-00483-01.2004-00483-01.

45 Consejo de Estado, Sala de lo Contencioso Administrativo, Sección Tercera, Subsección B, sentencia del 7 de abril de 2011, Rad. n. ${ }^{\circ}$ 25000-23-24-000-2000-00016-01(AG). Dispuso este fallo de acción de grupo que "Todo usuario al que se le haya cobrado en el año 2000 por concepto de honorarios de abogado al reconectársele el servicio luego de una suspensión del mismo, tiene derecho a que se le reembolse dicha suma, en tanto ello supuso un daño antijurídico que no tenía por qué soportar". 
por el legislador. No de otra forma se puede valorar el impacto que han tenido las acciones de tutela, populares y de cumplimiento sobre el modelo de prestación empresarial que quiso promover la LSPD, edificado sobre la idea de libre competencia de los operadores como clave de los beneficios que se esperaba ofrecer a la comunidad en general y a los usuarios en particular. Al resolver las numerosas reclamaciones interpuestas por la comunidad por medio de estas acciones, la jurisdicción contenciosa, revestida del manto de juez constitucional y muy en línea con los pronunciamientos de la Corte Constitucional, ha recordado a las empresas operadoras del sector y a las autoridades involucradas en él (incluyendo también a los ministerios, a las entidades territoriales y a las autoridades ambientales) que, pese a la liberalización operada en el sector, no se está frente a una actividad económica cualquiera, sino que se trata de servicios que son prioritarios para la comunidad e inberentes a la finalidad social del Estado. De su eficiente cobertura y calidad depende, en suma, la materialización efectiva de postulados constitucionales como la dignidad humana, el bienestar general o la calidad de vida de las personas.

La valiente y temprana jurisprudencia de la Corte Constitucional que adoptó las primeras sentencias con órdenes de construcción de acueductos y alcantarillados ${ }^{46}$ marcó una tendencia que luego sería profundizada por el Consejo de Estado como juez de acciones populares y principal responsable de la guarda y realización de los derechos colectivos, que ha resultado en una verdadera transformación del sector de los servicios públicos. Fallo tras fallo, al ordenar la realización de obras de acueducto y alcantarillado ${ }^{47}$ o de manejo de aguas residuales ${ }^{48}$, la reparación de redes $^{49}$ o su ampliación ${ }^{50}$, el cumplimiento de las normas técnicas sobre calidad del agua ${ }^{51}$, el cierre de rellenos sanitarios que no cumplen con la normativa ambiental ${ }^{52}$, la reubicación de viviendas ubicadas en zonas de ronda de río con riesgo de inundación ${ }^{53}$, la adopción de medidas para descontaminar cuerpos

46 Véanse, por ejemplo, las sentencias T-406 de 1992, T-570 de 1992, T-539 de 1993, T-244 de 1994 , T-092 de 1995 o Su 442 de 1997.

47 Cfr., p. ej., Consejo de Estado, Sala de lo Contencioso Administrativo, Sección Primera, la sentencia del 15 de junio de 2006, Rad. n. ${ }^{\circ}$ 25000-23-25-000-2002-00152-01(AP), o de 23 de octubre de 2014, Rad. n. ${ }^{\circ} 76001233100020110146201$.

48 Vid., entre otros, Consejo de Estado, Sala de lo Contencioso Administrativo, Sección Primera, sentencia del 30 de enero de 2014, Rad. n. ${ }^{\circ} 18001233100020110011101$, o de 6 de marzo de 2014, Rad. n. ${ }^{\circ}$ 73001233100020100069501 .

49 Véase, entre otras, de la Sección Quinta del Consejo de Estado, la sentencia de 4 de junio de 2001, Rad. n. ${ }^{\circ}$ 44001-23-31-000-2000-0421-01(AP-066). De la Sección Primera de la misma Corporación, los fallos del 20 de enero de 2005, Rad. No. 25000-23-25-000-2002-02261-01(AP), y del 10 de octubre de 2012, Rad. n. ${ }^{\circ}$ 17001-23-31-000-2010-00326-01(AP).

50 Consejo de Estado, Sala de lo Contencioso Administrativo, Sección Primera, sentencia del 7 de abril de 2011, Rad. n. ${ }^{\circ}$ 41001-23-31-000-2003-00900-01(AP).

51 Vid. Consejo de Estado, Sala de lo Contencioso Administrativo, Sección Primera, las sentencias del 20 de junio de 2002, Rad. n. ${ }^{\circ}$ 19001-23-31-000-2001-0946-01(AP), y del 16 de septiembre de 2010, Rad. n. ${ }^{\circ}$ 68001-23-15-000-2003-00425-01(AP).

52 Cfr., entre otras, Consejo de Estado, Sala de lo Contencioso Administrativo, Sección Primera, sentencia del 4 de mayo de 2011, Rad. n. ${ }^{\circ}$ 68001-23-15-000-2004-00523-01(AP).

53 Vid., p. ej., Consejo de Estado, Sala de lo Contencioso Administrativo, Sección Primera, sentencia del 15 de junio de 2006, Rad. n. ${ }^{\circ}$ 25000-23-25-000-2002-00152-01(AP). 
de agua ${ }^{54}$, la prestación de un servicio eficiente de recogida y manejo de basuras ${ }^{55}$ o la toma de medidas administrativas orientadas a asegurar la eficiente prestación de los servicios públicos ${ }^{56}$, el contencioso administrativo ha recordado a las autoridades públicas que en consideración a las implicaciones de los servicios públicos para la realización del Estado social de Derecho y de sus garantías fundamentales (dignidad humana, igualdad, solidaridad y condiciones materiales para el ejercicio de las libertades), pese al talante neoliberal del modelo de prestación impuesto por la ley, la dotación de infraestructuras adecuadas, la prevención de riesgos, la protección del medio ambiente y los recursos naturales y la garantía a la comunidad de un mínimo de acceso a servicios públicos de calidad constituyen compromisos fundamentales de las autoridades estatales. No es, pues, solo una cuestión de mercado.

Por este motivo, vía jurisprudencia el modelo de prestación establecido por la LSPD se ha terminado por desdoblar, dando paso a la puesta en marcha de una dimensión prestacional más constitucional que legal, no solo por ser las normas constitucionales las que le sirven de fundamento, sino también por ser claro que tal realidad no fue la inicialmente definida por el legislador, que estaba más focalizado en liberalizar el sector y en la visión de los operadores como empresarios y de las autoridades como reguladoras y fiscalizadoras de las actuaciones de éstos. Lo hecho por la Corte Constitucional en sede de tutela en relación con el derecho fundamental al agua ${ }^{57}$ a partir de su relación estrecha con la garantía del mínimo vital confirma esta realidad y pone en evidencia la existencia de otro modelo de prestación de servicios públicos paralelo al establecido por el legislador.

\section{CONCLUSIONES}

Los planteamientos anteriores obligan a reflexionar no solo sobre la extensión del control del contencioso sobre los actos de las autoridades y de los operadores del sector, que es mucho más amplio de lo que inicialmente se pensó y quizás de lo que originalmente se quiso. A la vista del recuento legal y jurisprudencial efectuado, es evidente que el contencioso sigue siendo boy, en parte muy importante, el juez de los servicios públicos. Ello no es más que la expresión del Estado de Derecho y de la legítima preocupación por la garantía de un control efectivo de la legalidad de todas las decisiones que adoptan no solo el gobierno

54 Cfr., e. g., Consejo de Estado, Sala de lo Contencioso Administrativo, Sección Primera, las sentencias de 15 de noviembre de 2012, Rad. n. ${ }^{\circ}$ 25000-23-24-000-2010-00524-01(AP); del 18 de mayo de 2011, Rad. n. ${ }^{\circ}$ 70001-23-31-000-2004-00794-01(AP); de 27 de octubre de 2011, Rad. n. ${ }^{\circ}$ 17001- 23-00-0002003-00866-01(AP) y, más recientemente, sobre la catástrofe ambiental del río Bogotá, el fallo del 28 de marzo de 2014, Rad. n. ${ }^{\circ}$ 25000-23-27-000-2001-90479-01(AP).

55 Véase, p. ej., Consejo de Estado, Sala de lo Contencioso Administrativo, Sección Primera, las sentencias del 17 de junio de 2010, Rad. n. ${ }^{\circ}$ 68001-23-15-000-2001-02351-01(AP), y del 18 de septiembre de 2014, Rad. n. ${ }^{\circ}$ 13001-23-31-000-2010-00825-01.

56 Cfr., p. ej., Consejo de Estado, Sala de lo Contencioso Administrativo, Sección Tercera, las sentencias del 26 de enero de 2006, Rad. n. ${ }^{\circ}$ 54001-23-31-000-2002-01944-01(AP), y del 19 de abril de 2007, Rad. n. ${ }^{\circ}$ 54001-23-31-000-2003-00266-01(AP).

57 Véanse, p. ej., las sentencias T-888 de 2008, T-381 de 2009, T-740 de 2011 o T-525 de 2012. 
y sus delegados sino también todas aquellas personas que a pesar de su condición de particulares ejercen, en el modelo de sociedad que tenemos hoy en día, funciones que antes fueron estatales y que han sido cedidas al mercado, sin que ello tenga la entidad suficiente para desvirtuar su naturaleza pública ni para diluir ni eclipsar los indiscutibles intereses generales que hay en ellas.

Pero esta situación fuerza también a reflexionar sobre la realidad del derecho de los servicios públicos. Se conmemoran hoy 20 años de un modelo que supuso una gran transformación para el sector en el país. Nada más propicio, entonces, que este aniversario, para someter a juicio crítico y realista la situación que vive el modelo, escindido hoy en dos planos: uno formalmente ajustado a la ley y basado en la lógica económica que esta quiso imponer, que opera sobre la base de unos operadores privados que actúan en libre competencia bajo las condiciones del regulador estatal y bajo la vigilancia de la autoridad de policía del sector, y otro acuñado por la jurisprudencia con soporte en la garantía de los derechos sociales consagrados por la Constitución, de claro corte prestacional estatista y más próximo a la visión clásica del servicio público que a su moderna concepción económica.

Dada la fuerza que da a la jurisprudencia el poder de decir cómo es el Derecho en el terreno (Derecho viviente) y las innegables implicaciones que tiene para un sector como éste y para la economía del país no tener uno sino dos modelos de prestación de servicios, son muchas las interrogantes que surgen de esta situación. Por esto, además de manifestar que pese a lo que en su momento pudo pretender el legislador, hoy se puede asegurar que el administrativo se resiste a dejar de ser el Derecho de los servicios públicos y el contencioso persiste en su vocación de juez del interés general y de los actos de autoridad (prerrogativas públicas). La ocasión obliga a preguntarse si tras 20 años de la expedición de la LSPD no será conveniente y necesario que ley y la jurisprudencia abran un espacio de diálogo que permita poner fin a esa dualidad de modelos con los que convivimos en Colombia casi desde el mismo momento en que entró en vigor la norma vigente. Quizás ello podría contribuir a resolver problemas actuales como la persistente falta de cobertura o de prestación eficiente de servicios básicos en muchos rincones del país.

\section{BIBLIOGRAFÍA}

Ariño OrTiZ, GaSPaR (2003). Principios de Derecho público económico. Bogotá: Universidad Externado de Colombia.

Atehortúa Ríos, Carlos Alberto (2006). Servicios públicos domiciliarios, proveedores y régimen de controles. Bogotá: Universidad Externado de Colombia.

Brewer Carías, Allan (1991). "Reflexiones sobre la constitución económica", en Estudios sobre la Constitución Española, t. V. Madrid: Civitas.

Consejo de Estado, Sala de lo Contencioso Administrativo, Sección Tercera, sentencia de 24 de febrero de 2005, Rad. n. ${ }^{\circ}$ 41001-23-31-000-2003-01470-01(AP).

Consejo de Estado, Sala de lo Contencioso Administrativo, Sección Tercera, auto del 8 de febrero de 2001, Exp. n. ${ }^{\circ} 16661$. 
Consejo de Estado, Sala de lo Contencioso Administrativo, Sección Tercera, sentencia del 27 de octubre de 2005, Rad. n. ${ }^{\circ}$ 11001-03-26-000-2002-00045-01(23583).

Consejo de Estado, Sala de lo Contencioso Administrativo, Sección Tercera, sentencia del 5 de marzo de 2008, Rad. n. ${ }^{\circ}$ 11001-03-26-000-2001-0029-01 (20.409).

Consejo de Estado, Sala de lo Contencioso Administrativo, Sección Tercera, sentencia del 2 de mayo de 2007, Rad. n. ${ }^{\circ} 11001-03-26-000-1998-05354-01$ (16257).

Consejo de Estado, Sala de lo Contencioso Administrativo, Sección Primera, sentencia del 21 de agosto de 2008, Rad. n. ${ }^{\circ}$ 11001-03-24-000-2003-00047-00.

Consejo de Estado, Sala de lo Contencioso Administrativo, Sección Primera, sentencia del 30 de abril de 2009, Rad. n. ${ }^{\circ} 11001032400020040012301$.

Consejo de Estado, Sala de lo Contencioso Administrativo, Sección Primera, sentencia del 28 de agosto de 2014, Rad. n. ${ }^{\circ} 25000232400020080036901$.

Consejo de Estado, Sala de lo Contencioso Administrativo, Sección Primera, sentencia del 21 de agosto de 2014, Rad. n. ${ }^{\circ}$ 25000-23-24-000-2008-00236-01.

Consejo de Estado, Sala de lo Contencioso Administrativo, Sección Primera, sentencia del 23 de febrero de 2012, Rad. n. ${ }^{\circ}$ 2004-00344.

Consejo de Estado, Sala de lo Contencioso Administrativo, Sección Primera, sentencia del 17 de agosto de 2000, Rad. n. ${ }^{\circ} 5920$.

Consejo de Estado, Sala de lo Contencioso Administrativo, Sección Primera, sentencia del 2 de noviembre de 2006, Rad. n. ${ }^{\circ}$ 20001-23-31-000-2004-00004-01(AP).

Consejo de Estado, Sala de lo Contencioso Administrativo, Sección Primera, sentencia del 23 de enero de 2014, Rad. n. ${ }^{\circ}$ 25000-23-24-000-2004-00633-02.

Consejo de Estado, Sala de lo Contencioso Administrativo, Sección Primera, sentencia del 4 de octubre de 2012, Rad. n. ${ }^{\circ}$ 2004-00483-01. 2004-00483-01.

Consejo de Estado, Sala de lo Contencioso Administrativo, Sección Primera, sentencia del 7 de abril de 2011, Rad. n. ${ }^{\circ}$ 41001-23-31-000-2003-00900-01(AP).

Consejo de Estado, Sala de lo Contencioso Administrativo, sentencia del 4 de agosto de 2011, Rad. n. ${ }^{\circ}$ 25000-23-24-000-2003-01151-01.

Consejo de Estado, Sala de lo Contencioso Administrativo, sentencia del 23 de agosto de 2012, Rad. n. ${ }^{\circ}$ 11001-03-24-000-2002-00070-01.

Consejo de Estado, Sala Plena de lo Contencioso Administrativo, auto del 23 de septiembre de 1997, Exp. S-701.

Correa Henao, Magdalena (2008). Libertad de empresa en el Estado Social de Derecho. Bogotá: Universidad Externado de Colombia.

Corte Constitucional, Sentencia C-1120 de 2005.

Corte Constitucional, Sentencia T-270 de 2004.

Gil Botero, ENRIQUE (2013). "El objeto de la jurisdicción de lo contencioso administrativo", en 100 años de jurisdicción administrativa. Bogotá: Consejo de Estado - Sala de Consulta y Servicio Civil.

Hernández BeCerra, Augusto (2011). "Cien años del Acto Legislativo n. ${ }^{\circ} 3$ de 1910", en Instituciones judiciales y democracia. Bogotá: Consejo de Estado - Sala de Consulta y Servicio Civil.

JÈZE, Gaston (s.f.). Principios generales del Derecho Administrativo, vols. 2 y 3.Buenos Aires: De Palma. 
Julio Estrada, AleXei (2000). "Economía y ordenamiento constitucional", en I Jornadas de Derecho Constitucional y Administrativo. Bogotá: Universidad Externado de Colombia.

Ley 142 de 1994 - Ley de Servicios Públicos Domiciliarios.

Ley 1480 de 2011 - Estatuto del Consumidor.

Marín CORTÉs, FABIÁn (2008). Público y privado. Las transformaciones del Derecho del Estado y de la Empresa. Bogotá: Temis.

Martín-Retortillobaquer, Sebastián (1996). El Derecho Civil en la génesis del Derecho Administrativo $y$ de sus instituciones. Madrid: Civitas.

Montaña Plata, Alberto (2005). El concepto de servicio público en el Derecho Administrativo, 2a Edición. Bogotá: Universidad Externado de Colombia.

Montaña Plata, Alberto (2011). Fundamentos de Derecho Administrativo. Bogotá: Universidad Externado de Colombia.

Palacios Mejía, Hugo (1999). El Derecho de los servicios públicos. Bogotá: Derecho Vigente.

SÁnChez LuQue, Guillermo (2014). “El Derecho administrativo sigue siendo el Derecho de los servicios públicos?", en Derecho Procesal Administrativo, modernización del Estado y Territorio. Estudios en bomenaje a Augusto Hernández Becerra (Ed. Germán Bula Escobar, Álvaro Namén VarGas y William Zambrano Cetina). Bogotá: Ibáñez - Sala de Consulta y Servicio Civil - Aida.

Santaella Quintero, Héctor (2001). "El modelo económico en la Constitución de 1991", en Revista de Derecho del Estado n. ${ }^{\circ} 11$.

Santofimio Gamboa, Jaime Orlando (2004). Tratado de Derecho Administrativo, t. III. Bogotá: Universidad Externado de Colombia.

SCHMidT-AssmanN, EBERHARD (2003). La teoría general del Derecho Administrativo como sistema. Madrid: INAP- Marcial Pons.

Velilla Moreno, Marco Antonio (1996). "Reflexiones sobre la Constitución Económica Colombiana", en Constitución Económica Colombiana. Bogotá: El Navegante. 